\title{
Linear Regression Model for Predictions of COVID- 19 New Cases and New Deaths Based on May/June Data in Ethiopia
}

\author{
Alemayehu Siffir Argawu ( $\sim$ alex089973@gmail.com ) \\ Ambo University https://orcid.org/0000-0002-4444-0513
}

\section{Research Article}

Keywords: COVID-19 New Cases, New Deaths, Number of Days, Laboratory Tests, New Recoveries, Correlation Coefficient, Linear Regression Model

Posted Date: August 19th, 2020

DOI: https://doi.org/10.21203/rs.3.rs-61667/v1

License: (ㅇ (i) This work is licensed under a Creative Commons Attribution 4.0 International License. Read Full License

Version of Record: A version of this preprint was published at International Journal of Theoretical and Applied Mathematics on August 19th, 2020. See the published version at https://doi.org/10.11648/j.ijtam.20200605.11. 


\section{Linear Regression Model for Predictions of COVID-19 New Cases and New Deaths Based on May/June Data in Ethiopia}

By Alemayehu Siffir Argawu (MSc)

alemayehu.siffir@ambou.edu.et alex089973@gmail.com

Department of Statistics, Ambo University

Ambo, Ethiopia

Introduction: On the $15^{\text {th }}$ of June 2020, we have 7,984,067 total COVID-19 cases, globally and 435,181 deaths. Ethiopia was ranked $2^{\text {nd }}$ and $15^{\text {th }}$ in the table by 176 new cases and by 3,521 total new cases from African countries. Then, this study aimed to predict COVID-19 new cases and new deaths based on May/June data in Ethiopia using a linear regression model.

Methods: In this study, I used Pearson's correlation analysis and the linear regression model to predict COVID-19 new cases and new deaths based on the available data from $12^{\text {th }}$ May to $10^{\text {th }}$ June 2020 in Ethiopia.

Results: There was a significant positive correlation between COVID-19 new cases and new deaths with different related variables. In the multiple linear regression model, variables such as the number of days, the number of new laboratory tests, and the number of new cases from AA city significantly predicted the COVID-19 new cases. In this model, the number of days and new recoveries significantly predicted new deaths of COVID-19.

Conclusions: The number of days, daily laboratory tests, and new cases from Addis Ababa city significantly predicted new COVID-19 cases, and the number of days and new recoveries significantly predicted new deaths from COVID-19. According to this analysis, if strong preventions and action are not taken in the country, the predicted values of COVID-19 new cases and new deaths will be 590 and 12 after two months (after $9^{\text {th }}$ of August) from now, respectively. The researcher recommended that the Ethiopia government, Ministry of Health and Addis Ababa city administrative should give more awareness and protections for societies, and they should also open more COVID-19 laboratory testing centres. Generally, the obtained results of this study may help Ethiopian decision-makers put short-term future plans to face this epidemic.

Keywords: COVID-19 New Cases, New Deaths, Number of Days, Laboratory Tests, Correlation Coefficient, Linear Regression Model 


\section{Introduction}

Corona virus disease (COVID-19) is an infectious disease that is caused by severe acute respiratory syndrome known as corona virus. The virus was first identified on 31 December 2019 in the city of Wuhan, which is the capital of Hubei Province in China [1]. Some of the common signs of COVID-19 include fever, shortness of breath and dry coughs [2]. Other uncommon symptoms include muscle pain, mild diarrhoea, abdominal pain, sputum production, loss of smell, and sore throat [3], [4]. On 11 March 2020, the WHO announced that it was a global pandemic [5].

On 15 June 2020, this pandemic affected nearly 8 million people. On this date, as the Worldometer corona virus updates information showed that we have 7,984,067 total COVID-19 cases globally and 435,181 deaths. It was distributed from highest to lowest ranks of the new cases and deaths by the World Regions as follows: North America has led by 2,480,701 total new cases $\left(1^{\text {st }}\right)$ and 144,979 total deaths $\left(2^{\text {nd }}\right)$, Europe has 2,398,779 total new cases $\left(2^{\text {nd }}\right)$ and 188,001 total deaths $\left(1^{\text {st }}\right)$, Asia has $1,616,962$ total new cases $\left(3^{\text {rd }}\right)$ and 40,248 total deaths $\left(4^{\text {th }}\right)$, South America has $1,425,696$ total new cases $\left(4^{\text {th }}\right)$ and 60,457 total deaths $\left(3^{\text {rd }}\right)$, Africa has 244,578 total new cases $\left(5^{\text {th }}\right)$ and 6,490 total deaths $\left(5^{\text {th }}\right)$, and the last in both ranks is Oceania, which has 8,931 cases and 124 deaths [6].

On this date, Ethiopia was ranked as the $2^{\text {nd }}, 15^{\text {th }}, 16^{\text {th }}$ and ${ }^{23 r d}$ on the table by 176 new cases, by 3,521 total COVID-19 cases, by 60 total deaths and by 620 total recoveries, respectively, from African countries as the Worldometer corona virus updates information shows. This report also shows that Ethiopia was listed on the $27^{\text {th }}$ position by the capacity of COVID-19 laboratory tests. It was 1,629 tests per 1,000,000 populations [6]. This is bad news for Ethiopia. Currently, the Ethiopian population is near 115 million. This is the fact that Ethiopia has a very low proportion of COVID-19 laboratory tests compared with other countries tests. These results indicate that Ethiopia needs increasing efforts and strategies to increase daily laboratory tests. Otherwise, she will be the next "African USA'.

Then, this study aimed to achieve the following objectives:

1. To predict COVID-19 new cases by daily laboratory tests in a linear regression model.

2. To predict COVID-19 new cases by the number of days.

3. To predict COVID-19 new cases by new cases from Addis Ababa city.

4. To predict new deaths by the number of days, COVID-19 new cases, and new recoveries. 


\section{Methodology}

\subsection{Data}

The COVID-19 new case report data were collected from the Ethiopia Ministry of Health and Ethiopian Public Heath Institution reports from their face book and telegram pages [7], [8]. 14th March 2020 was the first date that COVID-19 was confirmed in Ethiopia. The time period of data was from the 12th of May to the 10th of June 2020 (for the last 30 days). The data included the total number of new cases, date of recorded, number of new total COVID-19 cases, number of new deaths, number of new recoveries, number of persons who have contacted infected cases, number of male total COVID-19 cases, number of new cases from AA city, and others. In this study, I used Pearson's correlation analysis and the linear regression model to predict COVID-19 new cases based on the available data from 12th May to 10th June 2020 in Ethiopia.

\subsection{Regression Model}

Regression models are statistical sets of processes that are used to estimate or predict the target or dependent variable on the basis of independent variables. The regression model has many variants, such as linear regression, ridge regression, stepwise regression, and polynomial regression. Linear regression is a simple model that is used to find the relation between a dependent and an independent variable. Equation 1 shows the relationship between a dependent (COVID-19 new cases from 12th of May to 10th of June, 2020) and independent variables. Each univariate analysis in the linear regression model is used to show how much each independent variable will be predicted by the dependent variable. Multivariate analysis was also used to determine the most predicator variables for th total number of COVID-19 new cases from 12th May to 10th June 2020 in Ethiopia.

$$
Y=\beta_{0}+\beta_{1} X_{1}+\beta_{2} X_{2}+\cdots \beta_{p} X_{p}+\epsilon
$$

Where $Y$ is the total number of COVID-19 new cases and $X_{1}, X_{2}, \ldots$, and $X_{p}$ are p-independent. $\beta_{0}, \beta_{1}, \beta_{2}, \ldots$, and $\beta_{p}$ are the intercept and coefficients of the variables, respectively. $\boldsymbol{\epsilon}$ is the error term in the model. 


\section{Results and Discussion}

\subsection{Results}

\subsubsection{Frequency Statistics of COVID-19 Cases}

Total number of COVID-19 laboratory tests: The total numbers of COVID-19 laboratory tests were 158,521 and 121,938 from 14 of March to 10 of June and 12th of May to 10th of June, respectively. This indicates that the testing rate was increased to $77 \%$. The newly reported COVID-19 laboratory tests peaked at 6,092 on June 07, 2020.

Prevalence of COVID-19 cases: The total COVID-19 cases were 2,506 and 2,257 from 14 of March to 10 of June and from 12 of May to 10 of June, respectively. This indicates that new cases from 12th May to 10th June (duration of 30 days) were increased by 10 times from 14 March to 11 May (duration of 60 days). Thus, the prevalence of COVID-19 new cases increased from 158 to 185 per 10,000 laboratory tests per day from $12^{\text {th }}$ May to $10^{\text {th }}$ June in Ethiopia, 2020. The new cases peaked at 190 cases on June 09, 2020.

Death rate: The crude mortality or death rate was $1.4 \%$ (35) and $1.3 \%$ (30) from 14 to 10 June and from 12 May to 10 June, respectively. This showed that the death of COVID-19 was 6 times greater from $12^{\text {th }}$ May to $10^{\text {th }}$ June than from 14 March to 11 May in Ethiopia, 2020. New deaths peaked at 7 deaths on June $7^{\text {th }}$ in 2020 .

Recovery rate: The recovery rates were 16\% (401) and 13\% (294) from 14 March to 10 June and from 12 May to 10 June, respectively. In addition, $73.3 \%$ of the total recovered cases were reported from 12th May to 10th June in Ethiopia, 2020.

Table 1: Percentage and rates of COVID-19 cases from $14^{\text {th }}$ of March to 10 of June and from $12^{\text {th }}$ May to $10^{\text {th }}$ June in Ethiopia, 2020

\begin{tabular}{|l|l|c|c|}
\hline \multirow{2}{*}{ No. } & \multirow{2}{*}{ Variable } & \multicolumn{2}{|c|}{ Date } \\
\cline { 2 - 4 } & $\begin{array}{c}14^{\text {th }} \text { March to } 10^{\text {th }} \text { June } \\
(90 \text { days })\end{array}$ & $\begin{array}{c}12^{\text {th }} \\
\text { May to } 10^{\text {th }} \text { June } \\
(30 \text { days })\end{array}$ \\
\hline 1. & Daily laboratory tests & 158,521 & $121,938(77 \%)$ \\
\hline 2. & COVID-19 new cases & $2,506(1.58 \%)$ & $2,257(1.85 \%)$ \\
\hline 3. & New deaths & $35(1.4 \%)$ & $30(1.3 \%)$ \\
\hline 4. & New recoveries & $401(16 \%)$ & $294(13 \%)$ \\
\hline
\end{tabular}




\subsubsection{COVID-19 New Cases by Regions and Genders}

Table 2 below illustrates the percentages of COVID-19 cases by gender and region from 12th May to 10th June (for the last 30 days) in Ethiopia, 2020.

From the total number of 2,257 COVID-19 new cases, the majority (64\%) were male. Addis Ababa city has covered the majority (74\%) of the Pandemic. The Somali region (7\%) has taken the $2^{\text {nd }}$ highest coverage of the virus. Oromia and Amhara regions have equally shared the COVID-19 new cases (each 6\%). However, Tigray and other regions (such as SNNP, Afar, Harare, etc.) have taken only 3\% of COVID-19 new cases by each. In addition, foreign natives have received only $1 \%$ of the distribution.

From the history of infected cases, patients' contacts and travel histories not known accounted for the majority $(54 \%, 594)$ of the COVOD-19 total COVID-19 cases. The patients' travel history from abroad and contacts with other new cases covered 26\% (283) and 20\% (218), respectively. All these histories of the cases were considered from May $12^{\text {th }}$ to June $2^{\text {nd }}, 2020$.

Table 2: Prevalence of COVID-19 new cases by gender and region from $12^{\text {th }}$ May to $10^{\text {th }}$ June (for the last 30 days) in Ethiopia, 2020

\begin{tabular}{|c|l|c|c|c|}
\hline No. & \multicolumn{1}{|c|}{ Prevalence by Category } & \# of days & Total & $\%$ \\
\hline $\mathbf{1 .}$ & Gender & & 2,257 & 100 \\
\hline & Male & 30 & 1,441 & 64 \\
\hline & Female & 30 & 816 & 36 \\
\hline $\mathbf{2 .}$ & Region & 30 & 1,671 & 74 \\
\hline & Addis Ababa City & 30 & 130 & 6 \\
\hline & Oromia Region & 30 & 134 & 6 \\
\hline & Amhara Region & 30 & 78 & 3 \\
\hline & Tigray Region & 30 & 157 & 7 \\
\hline & Somali Region & 30 & 67 & 3 \\
\hline & Other Regions & 30 & 20 & 1 \\
\hline & Other (Foreign Natives) & 22 & 1,095 & 100 \\
\hline $\mathbf{3 .}$ & Patient's History & 22 & 218 & 26 \\
\hline & Case had travel history from abroad & 22 & 594 & 54 \\
\hline & Case had contact with confirmed case & & & 99 \\
\hline & Case hadn't known his/her contact \& travel history & & \\
\hline
\end{tabular}

\subsubsection{Descriptive Statistics of COVID-19 Cases}

Table 3 below demonstrates the descriptive statistics of the COVID-19 new cases from 12th May to 10th June in Ethiopia, 2020.

Daily laboratory tests: The average value of COVID-19 conducted laboratory tests was 4,065 per day with its min $(1,775)$ and $\max (6,187)$ in the given duration. 
COVID-19 new cases: The average value of COVID-19 new cases was 75 per day, with minimum and maximum values of 2 and 190, respectively. AA city had recorded the highest COVID-19 new cases (56) per day in the given duration.

The minimum and maximum ages of COVID-19 new cases: The average values of the minimum and maximum ages of COVID-19 new cases were 9.4 years and 71 years with their smallest and largest ages of 1 month and 115 years, respectively.

Table 3: Descriptive statistics of the COVID-19 cases from $12^{\text {th }}$ May to $10^{\text {th }}$ June (for the last 30 days) in Ethiopia, 2020

\begin{tabular}{|c|l|c|c|c|c|}
\hline No. & \multicolumn{1}{|c|}{ Variables } & Min. & Max. & Mean & S.D \\
\hline $\mathbf{1 .}$ & Daily laboratory tests & 1775 & 6,187 & 4,065 & 1,094 \\
\hline $\mathbf{2 .}$ & COVID-19 new cases & 2 & 190 & 75 & 57 \\
\hline & New cases from Addis Ababa city & 0 & 153 & 56 & 48 \\
\hline $\mathbf{3 .}$ & Minimum age of new cases & 0.1 & 24 & 9.4 & 6.9 \\
\hline $\mathbf{4 .}$ & Maximum age of new cases & 33 & 115 & 71 & 18 \\
\hline
\end{tabular}

\subsubsection{Correlation Analysis for COVID-19 New Cases}

The correlation analysis showed that there were significantly positive correlations between COVID-19 new cases and the number of days, daily laboratory tests, new cases of males, new cases of females, new cases from AA city, new cases from foreign natives, new cases with unknown contact and travel histories, and new cases with contact with infected persons (table 4).

\subsubsection{Correlation Analysis for New Deaths}

Additionally, the correlation analysis for new deaths showed that there were significantly positive correlations between the number of new deaths and the number of days, COVID-19 new cases, daily laboratory tests, new cases from AA city, new recoveries, new cases of males, new cases of females and maximum age of new cases. However, there was a significantly negative correlation between new deaths and the minimum age of new cases (Table 5).

\subsubsection{Simple Linear Regression Model for COVID-19 New Cases}

In the SLR, nine variables, such as the number of days, daily laboratory tests, new recoveries, new cases from males, new cases from females, new cases from Addis Ababa city, new cases from foreign natives, new cases that had contact with other infected persons and new cases that 
neither known the contact nor travel history, significantly predicted the COVID-19 new cases at the $1 \%$ and $5 \%$ level of significance in table 6 and figures $3-7$.

The fitted models for COVID-19 New Cases: $\widehat{Y}=\widehat{\boldsymbol{\beta}}_{0}+\widehat{\boldsymbol{\beta}}_{\boldsymbol{i}} \boldsymbol{X}_{\boldsymbol{i}}, \boldsymbol{i}=\mathbf{1}, 2,3, \ldots, 9$.

1) COVID $-\widehat{19 \mathrm{~N} e w}$ Cases $=-378+\mathbf{5 . 9} *$ number of days.

New cases will be increased to 590 after 100 days.

2) COVID $-\overline{19 \mathrm{~N} e w}$ Cases $=-61+\mathbf{0 . 0 3 4} *$ daily laboratory tests.

$>$ New cases will be raised to 3,400 if 100,000 laboratory tests are conducted.

3) COVID $-\overline{19 \mathrm{~N} e w}$ Cases $=57.3+\mathbf{1 . 8 3} *$ new recoveries.

New cases will be increased by 183 if 100 cases are recovered. This may be because people are neglected to take measurements on COVID-19.

4) COVID $-\overline{19 \mathrm{~N}}$ ew Cases $=-0.63+\mathbf{1 . 5 8} *$ new cases of males.

$>$ New cases will be raised to 1,580 when new cases of males increase by 1,000 .

5) COVID $-\widehat{19 \mathrm{~N} e w}$ Cases $=9.7+2.4 *$ new cases of female.

$>$ New cases will be raised to 2,400 as the new cases of females increase by 1,000.

- Comparing the male and female new cases, the females will infect more after times.

6) COVID $-\widehat{19 \mathrm{~N} e w}$ Cases $=10.8+1.2 *$ new cases from Addis Ababa city.

$>$ New cases will be increased by 12,000 for 10,000 new cases from AA city. This may be because the infected persons will travel to other regions from AA city.

7) COVID $-\widehat{19 \mathrm{~N} e w}$ Cases $=26.2+\mathbf{2 . 3 8} *$ new cases had contact with infected persons.

$>$ New cases will be increased by 2,380 because 1,000 new cases had contact with infected persons.

8) COVID1 $\widehat{9 \text { NewCases }}=18+\mathbf{1 . 2} *$ new cases had unknown contact and travel histories.

$>$ New cases will be increased by 1,200 for 1,000 new cases with unknown contact and travel histories.

9) COVID $-\widehat{19 \mathrm{~N}}$ ew Cases $=62.5+19.2 *$ new cases from foreign natives.

$>$ New cases will be increased by 19,200 for 1,000 new cases from foreign natives.

\subsubsection{Simple Linear Regression Model for New Deaths due to COVID-19}

In the SLR, nine variables, including the number of days, daily laboratory tests, COVID-19 new cases, new recoveries, new cases from Addis Ababa city, new cases of males, new cases of females, minimum age of new cases, and maximum age of new cases, significantly predicted the new deaths at the $1 \%$ and $5 \%$ levels of significance (table 7 and figures 8 and 9).

The fitted models for new deaths due to COVID-19: $\widehat{Y}=\widehat{\boldsymbol{\beta}}_{0}+\widehat{\boldsymbol{\beta}}_{i} \boldsymbol{X}_{\boldsymbol{i}}, \boldsymbol{i}=1,2,3, \ldots, 9$. 
1) New Deaths $=-8.6+\mathbf{0 . 1 2 4} *$ number of days.

New deaths will be increased by 12 after 100 days.

2) New Deaths $=-1.8+\mathbf{0 . 0 0 1} *$ daily laboratory tests.

New deaths will be increased by 100 if 100,000 laboratory tests are conducted.

3) New Deaths $=-0.23+\mathbf{0 . 0 1 6} *$ COVID -19 new cases.

$>$ New deaths will be raised by 16 when the new cases increase to 1000 .

4) New Deaths $=-0.02+\mathbf{0 . 1 0 4} *$ new recoveries.

$>$ New deaths will be increased by 104 if 1,000 cases are recovered. This may be due to other corresponding reasons.

5) New $\widehat{\text { Deaths }}=-0.2+\mathbf{0 . 0 3} *$ new cases of males.

$>$ New deaths will be raised by 30 as the new cases of males increase by 1,000.

6) New $\widehat{\text { Deaths }}=-1.2+\mathbf{0 . 0 4} *$ new cases of female.

$>$ New deaths will be raised to 40 when the new cases of females increase by 1,000 .

- Comparing the deaths by sex groups, the female group will count more deaths.

7) New $\widehat{\text { Deaths }}=-0.05+\mathbf{0 . 0 2} *$ new cases from Addis Ababa city.

New deaths will be increased to 200 for 10,000 new cases from Addis Ababa city.

8) New Deaths $=2.0+-0.11 *$ minimum age of new cases.

$>$ New deaths will decline to 1 when the minimum age of the case is increased by 10 .

9) New Deaths $=-1.7+0.04 *$ maximum age of new cases.

New deaths will be raised to 0.4 when the maximum age of the case is increased by 10 .

\subsubsection{Multiple Linear Regression (MLR) Model for COVID-19 New Cases}

In this model, COVID-19 new cases were predicted significantly by the number of days, daily laboratory tests and new cases from Addis Ababa city at the 5\%,10\% and 1\% levels of significance, respectively.

Thus, the fitted MLR for COVID-19 New Cases: $\widehat{Y}=\widehat{\boldsymbol{\beta}}_{0}+\widehat{\boldsymbol{\beta}}_{1} \boldsymbol{X}_{1}+\widehat{\boldsymbol{\beta}}_{2} \boldsymbol{X}_{2}+\widehat{\boldsymbol{\beta}}_{3} \boldsymbol{X}_{3}$.

COVID $-\widehat{19 \mathrm{~N} e w}$ Cases $=-99.1+1.352 *$ number of days $+0.00503 *$

daily laboratory tests $+\mathbf{0 . 8 8 0 9 6} *$ new cases from AA city.

COVID-19 new cases are predicted to increase 135 when the number of days increases by 100 days while holding other variables constant.

COVID-19 new cases are predicted to increase 503 when the daily laboratory tests raise by 100,000 tests while holding other variables constant.

COVID-19 new cases are predicted to increase 881 when the new cases from Addis Ababa city increase by 10,000 tests while holding other variables constant. 
In addition, it is predicted to be 0 (negative cases not applicable) when the three variables are zero.

In the model, $\mathrm{R}^{2}=96 \%$ of the variation in COVID-19 new cases was explained by the model (predictors). In the hypothesis test (F-statistic $=205.1$ with $\mathrm{DF}=3 \& 26, \mathrm{p}$-value $=0.000)$, there was enough evidence to reject the null hypothesis that all the model's coefficients are 0 . The residual standard error $=12.16$ shows how far the observed total COVID-19 new cases (Yvalues) are from the predicted total COVID-19 new cases $(\hat{Y})$ (Figure 1, R-software output).

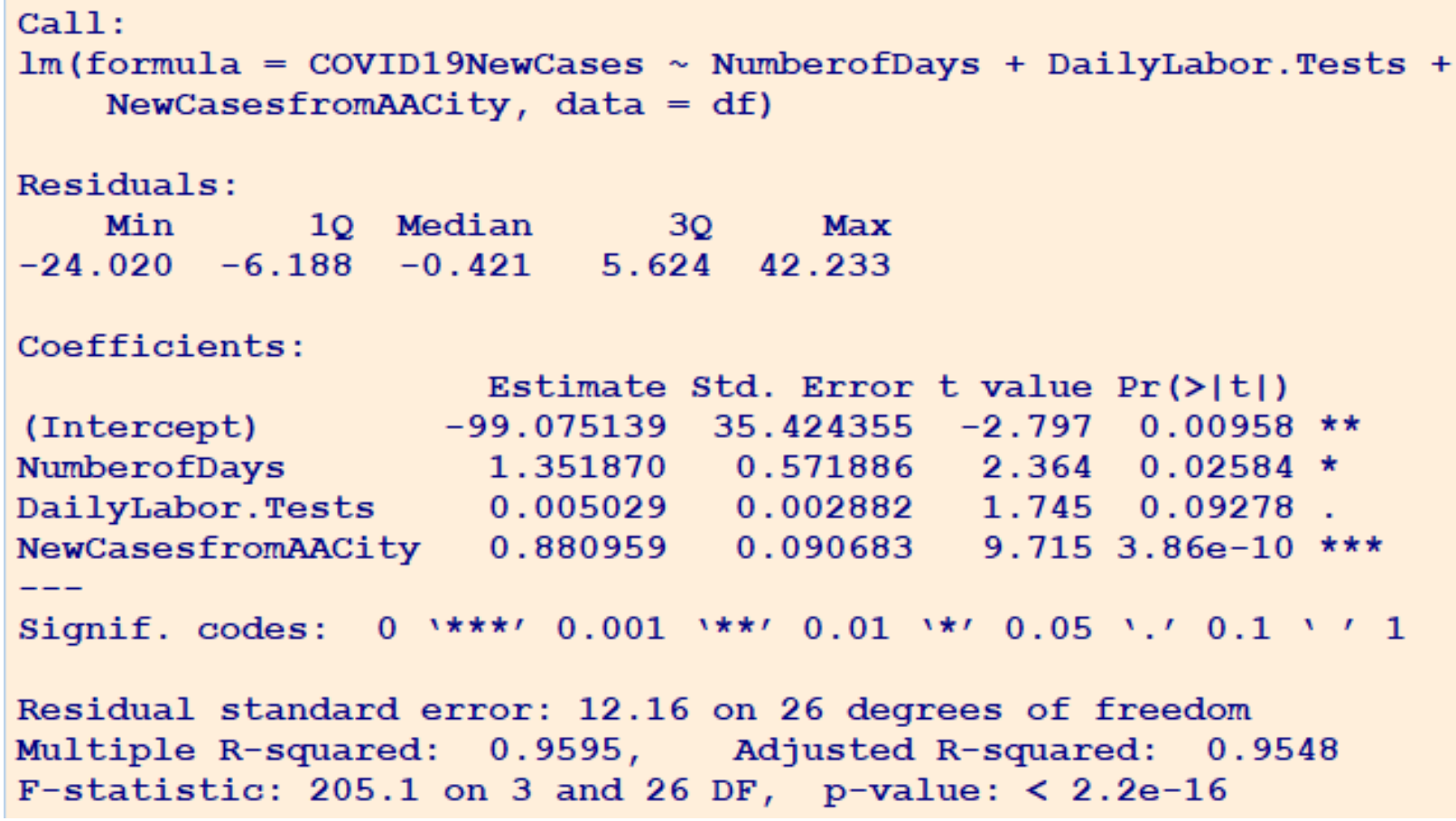

Figure 1: R Output of MLR for estimating the parameter to predict COVID-19 New Cases.

\subsubsection{Multiple Linear Regression (MLR) Model for New Deaths due to COVID-19}

In this model, new deaths due to COVID-19 were predicted significantly by the number of days and new recoveries at the $10 \%$ and $1 \%$ levels of significance, respectively.

Thus, the fitted MLR for new deaths due to COVID-19: $\widehat{Y}=\widehat{\boldsymbol{\beta}}_{0}+\widehat{\boldsymbol{\beta}}_{1} \boldsymbol{X}_{1}+\widehat{\boldsymbol{\beta}}_{2} \boldsymbol{X}_{2}$

\section{New Deaths $=-4.22+0.057 *$ number of days $+0.0789 *$ new recoveries.}

New deaths due to COVID-19 are predicted to increase by 6 when the number of days increases by 100 days while holding other variables constant.

New deaths are predicted to increase 79 when the new recoveries rise by 1,000 tests while holding other variables constant.

In addition, it is predicted to be 0 (negative deaths not applicable) when the two variables are zero. 
In the model, $\mathrm{R}^{2}=62.4 \%$ of the variation in new deaths was explained by the model (predictors). In the hypothesis test $(\mathrm{F}$-statistic $=22.4$ with $\mathrm{DF}=2 \& 27, \mathrm{p}$-value $=0.000)$, there was enough evidence to reject the null hypothesis that all the model's coefficients are 0 . The residual standard error $=1.07$ shows how far the observed new deaths (Y-values) are from the predicted new deaths $(\hat{Y})$ (Figure 2, R-software output).

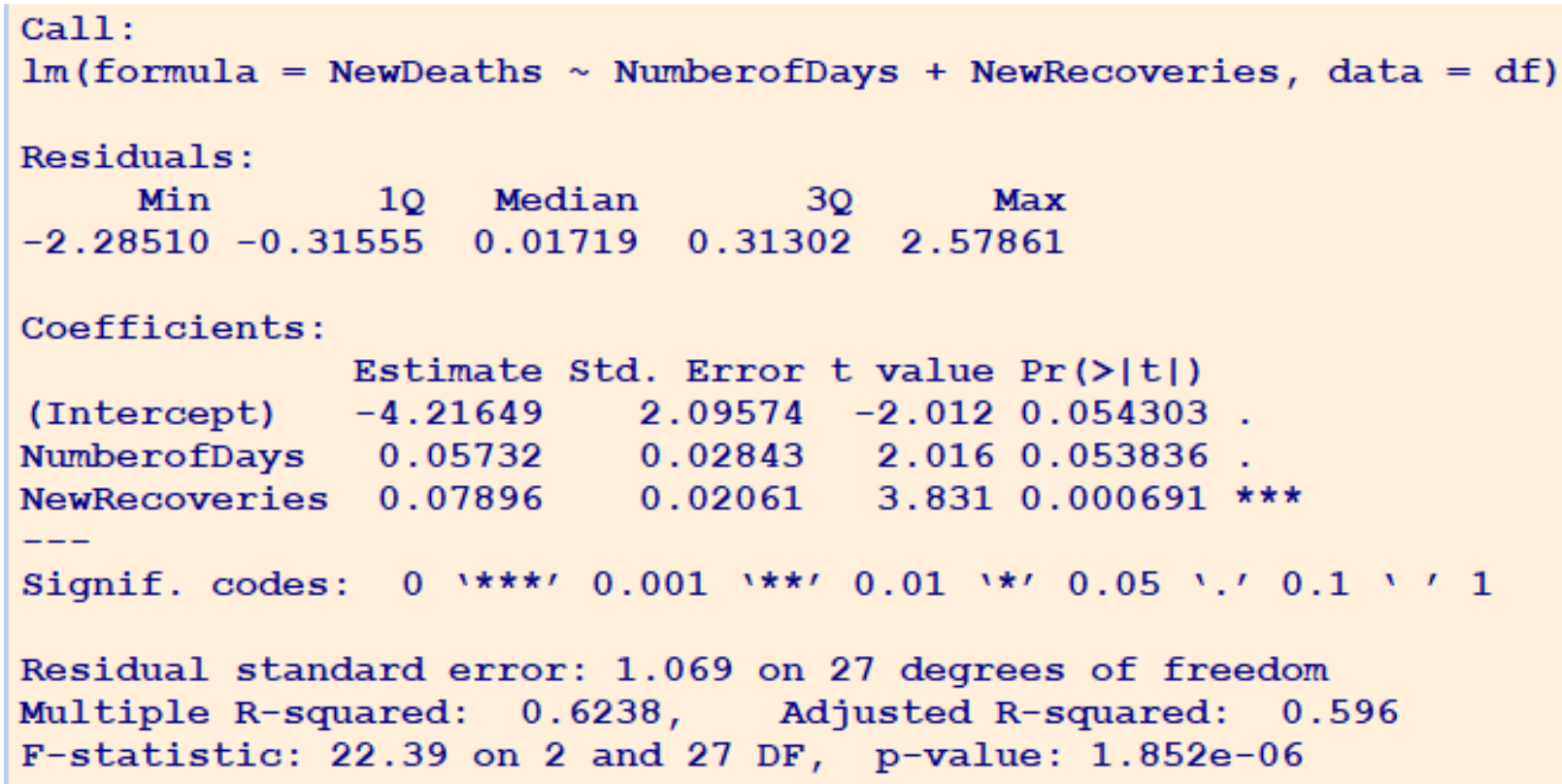

Figure 1: R-Output of MLR for estimating the parameter to predict new deaths of COVID-19

\subsection{Discussion}

In the correlation analysis for COVID-19, new cases had significant and positive correlations with the number of days $(r=0.901)$, daily laboratory tests $(r=0.641)$, new recoveries $(r$ $=0.389)$, new cases from males $(r=0.985)$, new cases from females $(r=0.964)$, new cases from AA city $(r=0.965)$, new cases from foreign natives $(r=0.416)$, new cases had unknown contact and travel histories $(r=0.958)$, and new cases had contacts with infected persons $(r=0.534)$.

In the correlation analysis, new deaths due to COVID-19 were significantly and positively correlated with the number of days $(r=0.648)$, COVID-19 new cases $(r=0.555)$, daily laboratory tests $(r=0.445)$, new cases from AA city $(r=0.533)$, new recoveries $(r=0.753)$, new cases of male $(r=0.53)$, new cases of female $(r=0.562)$ and the maximum age of new cases $(r=0.400$, weak). However, it was significantly and negatively correlated with the minimum age of new cases $(r=-0.426)$.

In the simple linear regression, COVID-19 new cases were significantly predicted by the number of days $(B=5.9)$, daily laboratory tests $(B=0.0334)$, new recoveries $(B=1.83)$, new cases of males $(B=1.58)$, new cases of females $(B=2.4)$, new cases from Addis Ababa city 
$(B=1.2)$, new cases from foreign natives $(B=19.2)$, new cases that had contact with other infected persons $(B=2.38)$, and new cases had unknown contact and travel histories $(B=1.2)$.

In the simple linear regression, new deaths were significantly predicted by the number of days $(B=0.124)$, COVID-19 new cases $(B=0.016)$, daily laboratory tests $(B=0.001)$, new recoveries $(B=0.104)$, new cases from Addis Ababa city $(B=0.019)$, new cases of male $(B=0.025)$, new cases of female $(B=0.041)$, minimum age of new cases $(B=-0.104)$ and maximum age of new cases $(B=0.037)$ were significantly predicted new deaths at the $1 \%$ and $5 \%$ levels of significance.

In the multiple linear regression model, COVID-19 new cases were predicted significantly by the number of days, daily laboratory tests and new cases from Addis Ababa city at the 5\%, 10\% and $1 \%$ levels of significance, respectively. Thus, COVID-19 new cases are predicted to increase 135, 503 and 881 when the number of days increases by 100 days, the daily laboratory tests increase by 100,000 tests, and the new cases from Addis Ababa city increase by 10,000 tests while holding other variables constant.

In the multiple linear regression model, new deaths due to COVID-19 were predicted significantly by the number of days and new recoveries at the $10 \%$ and $1 \%$ levels of significance, respectively. Thus, new deaths due to COVID-19 were predicted to increase 6 and 79 when the number of days increased by 100 days and the new recoveries rose by 1,000 tests while holding other variables constant, respectively.

This study agreed with a study from Kenya showing that there was a correlation between COVID-19 new cases and contact persons made by the confirmed status as well as the number of flights from foreign countries to Kenya. The study using univariate analysis of the generalized linear model showed that contact persons in Kenya had 0.265 effects on COVID-19 cases in Kenya. In the multivariate analysis, the contact persons and flights to Kenya had 0.278 and 3,309 effects on COVID-19 cases in Kenya at the 5\% and 10\% levels of significance, respectively. Researchers in Kenya also used the compound Poisson regression model, which showed that as the COVID-19 day increased by 235, the COVID-19 new cases were projected to 83,418 new cases [9].

A study from India used a linear regression analysis to predict the average week 5 and 6 death counts. In the study, there was a strong correlation between weeks 5 and 6 death counts with total cases, active cases, recoveries, and week 4 death counts. Despite this, the week 4 variables 
(total cases, active cases, and recoveries) were not significantly predicted by weeks 5 and 6 deaths count. However, the week 4 death count significantly predicted the week 5 death count. Therefore, my study agreed with this study on the correlation analysis but not on the linear regression analysis [10].

Another study from India used simple linear regression analysis of the number of deaths as a function of the number of confirmed cases. In this study, the coefficient of determination $\left(\mathrm{R}^{2}\right)$ was calculated to be 0.997 , which implies a strong linear correlation between confirmed and dead cases [11]. My study also found that there was a moderate linear correlation between new deaths and new cases $(\mathrm{r}=0.555)$. The study also used a simple linear regression analysis for the number of recovered cases as a function of the number of confirmed cases for India, and their calculated $\mathrm{R}^{2}$ was 0.984 , implying a linear correlation between confirmed and recovered cases (as on the $26^{\text {th }}$ of May 2020). In addition, my study also supported this result that there was a linear correlation between new COVID-19 cases and new recoveries with $r=0.389$. In my study, the new cases and new deaths were significantly predicted by the new recoveries with regression coefficients of 1.83 and 0.104 , respectively.

\subsection{How does this analysis help?}

The study used simple and multiple linear regression models to predict COVID-19 new cases as the number of days (reported date) increased, as the number of daily laboratory tests increased, and as the number of new cases from Addis Ababa city increased. It is also used to predict new deaths as the number of days increases, as the number of new cases increases, and as the maximum and minimum ages of new cases increase. I speculate the need for more urgent interventions (which are being taken again now) to prevent these extreme increments and spread through the country, especially in Addis Ababa city. More recommendations are mentioned below.

\subsection{Limitations of this analysis}

The main limitation of this analysis was that the data were not found together as collectively for all the previous reports and were taken from the face book and telegram pages of Ethiopia Ministry of Health. Second, limiting my analysis was that some data values were missed to report for 8 dates (such as the contact and travel history of the cases).

\subsection{Strength of the study}

Despite all the limitations, the greatest strength of this study was the very high adjusted $\mathrm{R}^{2}$ found in the predictive model. Three predictors for COVID-19 new cases were found in the 
multiple linear regression model, and its assumptions were fitted. In addition, there was crossvalidation with two different software programs (R and SPSS).

\section{Conclusions and Recommendations}

\subsection{Conclusions}

There were 2,506 total COVID-19 cases and 35 deaths due to COVID-19 with a crude mortality of $1.4 \%$ from 14 th march to $10^{\text {th }}$ June in Ethiopia, 2020. However, the total cases and total deaths of COVID-19 were 10 times and 6 times more, respectively, from the $12^{\text {th }}$ of May to the $10^{\text {th }}$ of June compared to the 14th of March to the $11^{\text {th }}$ of May 2020 in Ethiopia.

In the correlation analysis, the COVID-19 new cases were significantly correlated with the number of days, daily laboratory tests, new recoveries, new cases of males, new cases of females, new cases from Addis Ababa city, new cases with unknown contact and travel histories, and new cases that had contacts with infected persons.

In the correlation analysis, the new deaths due to COVID-19 were significantly correlated with the number of days, daily laboratory tests, COVID-19 new cases, new recoveries, new cases of males, new cases of females, new cases from Addis Ababa city, maximum age of new cases, and minimum age of new cases.

In the simple linear regression, variables such as the number of days (coefficient $B=5.9$ ), daily laboratory tests (coefficient $B=0.0334)$, new recoveries $(B=1.83)$, new cases of males $(B=1.58)$, new cases of females $(B=2.4)$, new cases from Addis Ababa city $(B=1.2)$, new cases from foreign natives $(B=19.2)$, new cases that had contact with other infected persons $(B=2.38)$, and new cases with unknown contact and travel histories $(B=1.2)$ significantly predicted COVID-19 new cases.

In the simple linear regression model, variables such as the number of days $(B=0.124)$, COVID19 new cases $(B=0.016)$, daily laboratory tests $(B=0.001)$, new recoveries $(B=0.104)$, new cases from Addis Ababa city $(B=0.019)$, new cases of males $(B=0.025)$, new cases of females $(B=0.041)$, minimum age of new cases $(B=-0.104)$ and maximum age of new cases $(B=0.037)$ significantly predicted new deaths.

In the multiple linear regression model, variables of the number of days, daily laboratory tests and new cases from Addis Ababa city significantly predicted COVID-19 new cases at the 5\%, $10 \%$ and $1 \%$ levels of significance, respectively. Thus, COVID-19 new cases are predicted to 
increase 135, 503 and 881 when the number of days increases by 100 days, the daily laboratory tests increase by 100,000 tests, and the new cases from Addis Ababa city increase by 10,000 tests while holding other variables constant.

In the multiple linear regression model, variables of the number of days and new recoveries are predicted new deaths due to COVID-19 at the $10 \%$ and $1 \%$ levels of significance, respectively. Thus, new deaths due to COVID-19 were predicted to increase 6 and 79 when the number of days increased by 100 days and the new recoveries rose by 1,000 tests while holding other variables constant, respectively.

Finally, according to this analysis, if strong preventions and action are not taken in the country, the predicted values of COVID-19 new cases and new deaths will be 590 and 12 after two months (after $9^{\text {th }}$ of August) from now, respectively.

\subsection{Recommendations}

Even if Ethiopia has taken strong measures, including complete lockdown of both its internal and external borders and announced the command posts and keeping social isolation for the last three months, the number of new cases and deaths due to COVID-19 new cases were highly increased day to day. The research has predicted the total number of COVID-19 new cases where it is easy to see how it is likely to progress in the future. The above information should help the government make plans on how to deal with pandemics, especially when dealing with the current situation in Ethiopia.

The prevalence of the disease and its crude mortality from 12th May to 10th June 2020 increased more and more, and Ethiopia might be one of the top countries from Africa by leading this Pandemic for the next months if very strong necessary measures will not be taken into consideration. The government must come up with more isolation beds, more trained health care professionals, and more mass education and campaigns with the aim of ensuring that the public has information about how to stop the spread of the virus. Let us consider that a huge population of the Ethiopia population lives in rural areas, more education as well as infrastructure must be done in the rural area to make preparations in case the COVID-19 finds its way more for the districts and the villages.

Moreover, the Ethiopia government, the Ministry of Health and Regional Governments (especially the AA city administrative and Somali region) should give more awareness and protections collaboratively for societies, and they should also open more COVID-19 laboratory testing health centres in different areas of the country to ensure that those health centres can test 
more persons as the number of days increases, and the number of new cases will be highly increased. With these preventive and curative measures, the severity of COVID-19 will be limited when compared to other countries, such as the USA, South Africa and Egypt, which are now leading in the number of new cases and deaths in the world and in Africa. This research work will be extended after looking for the spread of the disease instantaneously by using a comparison of linear regression and nonlinear regression models.

Abbreviations: AA-Addis Ababa city, CI-Confidence Interval, MLR-Multiple Linear Regression, and SLR-Simple Linear Regression

\section{Data Availability}

The data are available if required.

Funding

The research work was not supported by anyone.

\section{Conflict of interest}

The author has no conflicts of interest related to this research work.

\section{Author contributions}

All research was performed by Alemayehu Siffir Argawu. He was the only author of the research.

\section{Acknowledgments}

The data was collected from the daily reports of Ethiopia Ministry of Health's face book and telegram addresses from $12^{\text {th }}$ May to $10^{\text {th }}$ June 2020. So, really I acknowledged Ethiopia Ministry of Health (https://www.facebook.com/EthiopiaMoH). 


\section{References}

[1] S. Key and M. Infor, "LARGE-SCALE SCREENING OF PEOPLE INFECTED WITH COVID-19 IN AN ACCURATE."

[2] "Report of the WHO-China Joint Mission on Coronavirus Disease 2019 ( COVID-19)," vol. 2019, no. February, pp. 16-24, 2020.

[3] Q. Ge, L. Jin, and M. Xiong, "Artificial Intelligence Forecasting of Covid-19 in China Artificial Intelligence Forecasting of Covid-19 in China,” no. April, 2020.

[4] Z. Tao, J. Tian, Y. Pei, M. Yuan, Y. Zhang, and F. Dai, "A new coronavirus associated with human respiratory disease in China," vol. 579, no. March, 2020, doi: 10.1038/s41586-020-2008-3.

[5] W. H. O. Director-general, "WHO Director-General' s opening remarks at the media briefing on COVID-19 - 11 March 2020,” no. March, pp. 4-7, 2020.

[6] S. Asia, "Coronavirus disease," no. June, 2020.

[7] E. G. Organization, S. All, S. All, and S. All, "Ministry of Health, Ethiopia Photos," vol. 2020, no. 14, pp. 1-12, 2020.

[8] E. Medical, S. All, and S. All, "Ethiopian Public Health Institute Photos,” vol. 2020, no. 14, pp. 1-10, 2020.

[9] J. O. Odhiambo, P. Ngare, P. Weke, and R. O. Otieno, "Modelling of COVID-19 Transmission in Kenya Using Compound Poisson Modelling of COVID-19 Transmission in Kenya Using Compound Poisson Regression Model," no. May, 2020, doi: 10.9734/JAMCS/2020/v35i230252.

[10] P. Chauhan Poonam, Ashok Kumar Jamdagni, "Regression Analysis of COVID-19 Spread in India and its Different States," no. January, 2020.

[11] P. Chauhan, A. Kumar, P. Jamdagni, and D. Physics, "Regression Analysis of COVID-19 Spread in India and its Different," vol. 2020, no. March, pp. 1-14, 2020. 


\section{Figures}

Call:

lm(formula = COVID19NewCases $\sim$ NumberofDays + DailyLabor.Tests + NewCasesfromAACity, data $=$ df)

Residuals :

Min $1 Q$ Median $3 Q \quad$ Max

$\begin{array}{lllll}-24.020 & -6.188 & -0.421 & 5.624 & 42.233\end{array}$

Coefficients :

(Intercept)

NumberofDays

DailyLabor. Tests

NewCasesfromAACity
Estimate std. Error $t$ value $\operatorname{Pr}(>|t|)$ $-99.075139 \quad 35.424355$

1. 351870

0.571886

0.002882

$-2.797$

2.364

1.745

0.8809590 .090683
$0.00958 * \star$

0.02584 *

0.09278 .

$9.7153 .86 e-10 * \star *$

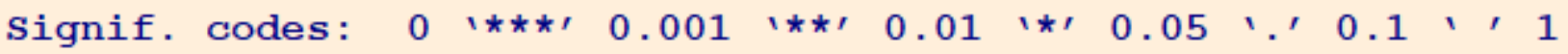

Residual standard error: 12.16 on 26 degrees of freedom

Multiple R-squared: $0.9595, \quad$ Adjusted R-squared: 0.9548

F-statistic: 205.1 on 3 and 26 DF, p-value: $<2.2 e-16$

\section{Figure 1}

R Output of MLR for estimating the parameter to predict COVID-19 New Cases.

Call:

$\operatorname{lm}$ (formula $=$ NewDeaths $\sim$ NumberofDays + NewRecoveries, data $=\mathrm{df}$ )

Residuals :

$$
\text { Min } 1 Q \quad \text { Median } 3 Q \quad \text { Max }
$$

$\begin{array}{lllll}-2.28510 & -0.31555 & 0.01719 & 0.31302 & 2.57861\end{array}$

Coefficients :

$\begin{array}{lrrrr} & \text { Estimate } & \text { std. Error } t \text { value } \operatorname{Pr}(>|t|) & \\ \text { (Intercept) } & -4.21649 & 2.09574 & -2.012 & 0.054303\end{array}$.

$---$

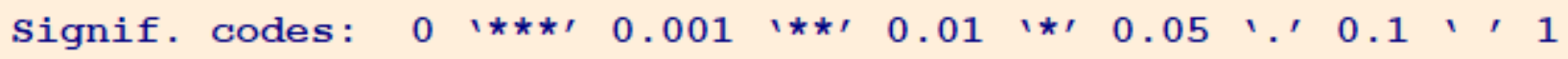

Residual standard error: 1.069 on 27 degrees of freedom

Multiple R-squared: $0.6238, \quad$ Adjusted R-squared: 0.596

F-statistic: 22.39 on 2 and 27 DF, p-value: $1.852 \mathrm{e}-06$

Figure 2

R-Output of MLR for estimating the parameter to predict new deaths of COVID-19 


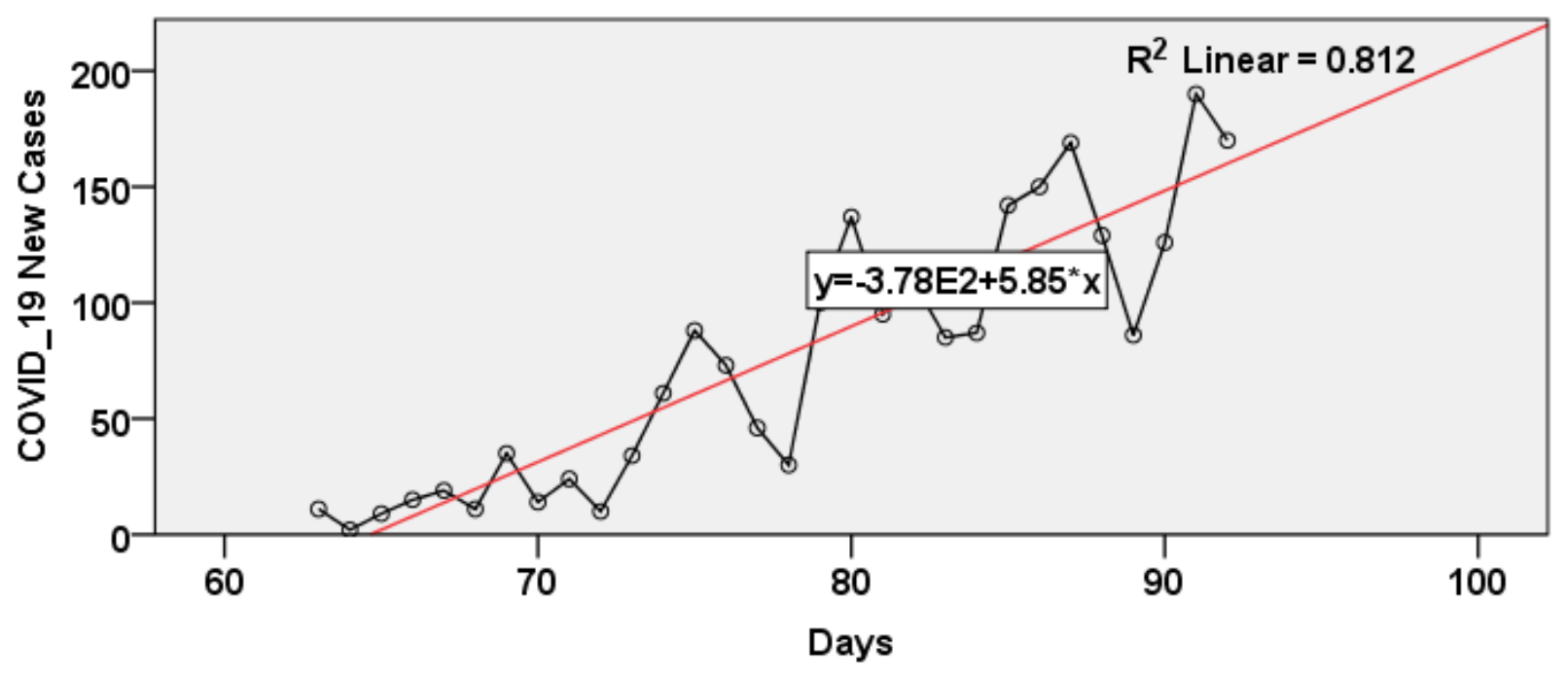

Figure 3

Simple line graph of COVID-19 new cases by the number of days

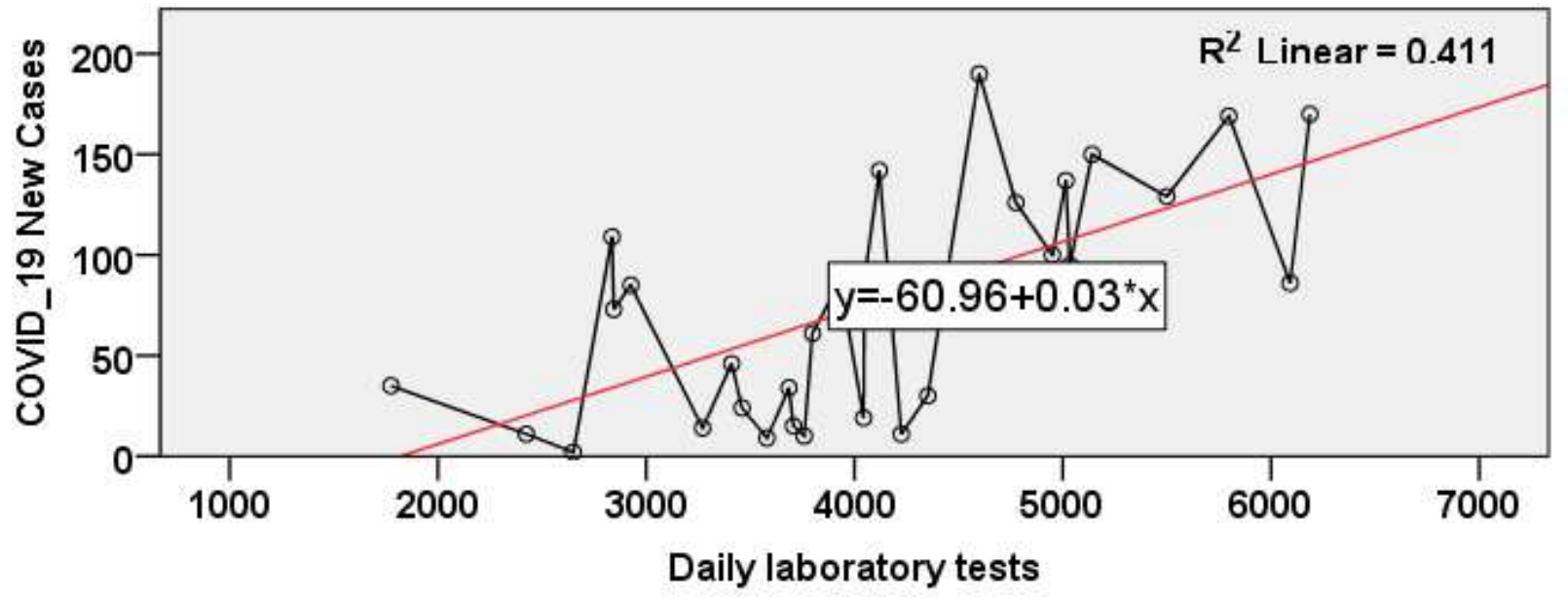

Figure 4

Simple line graph of COVID-19 new cases by daily laboratory tests 


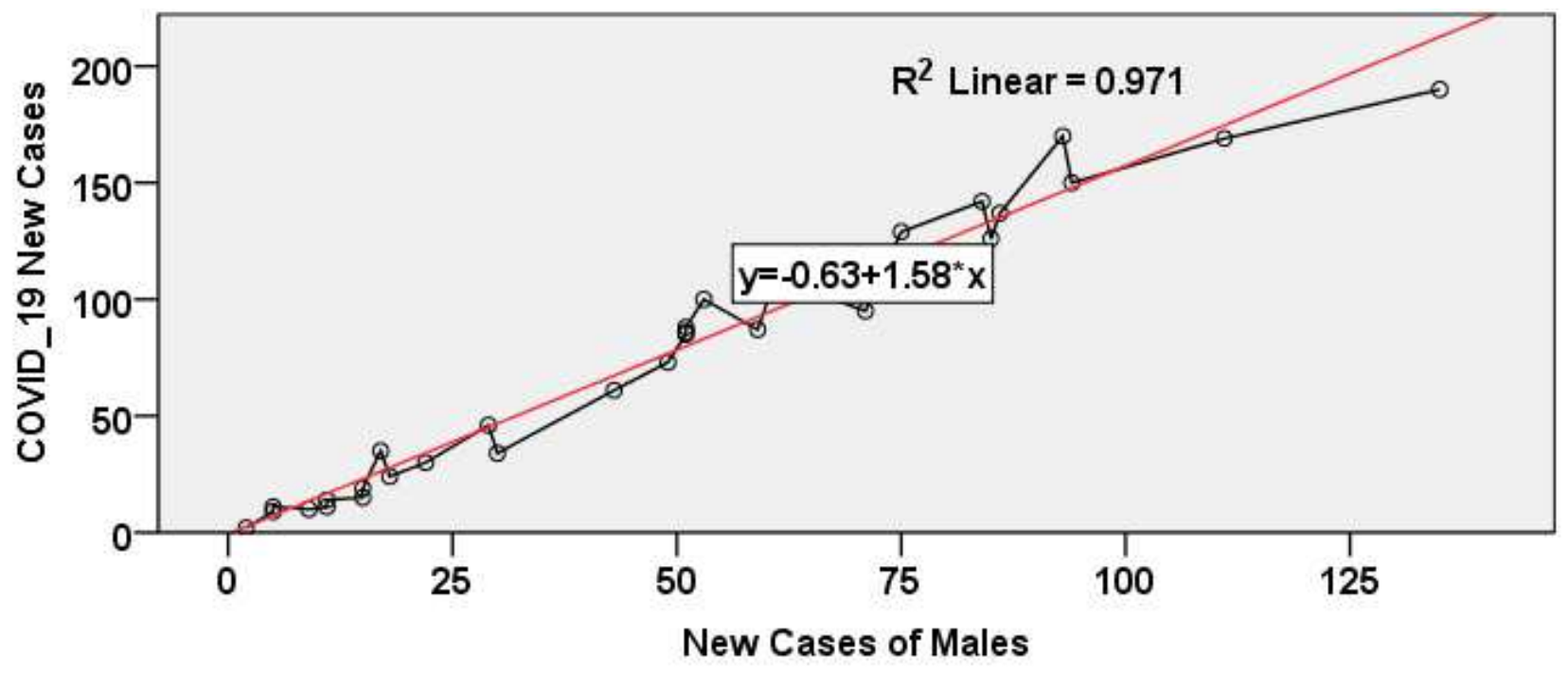

Figure 5

Simple line graph of COVID-19 new cases by new cases of males

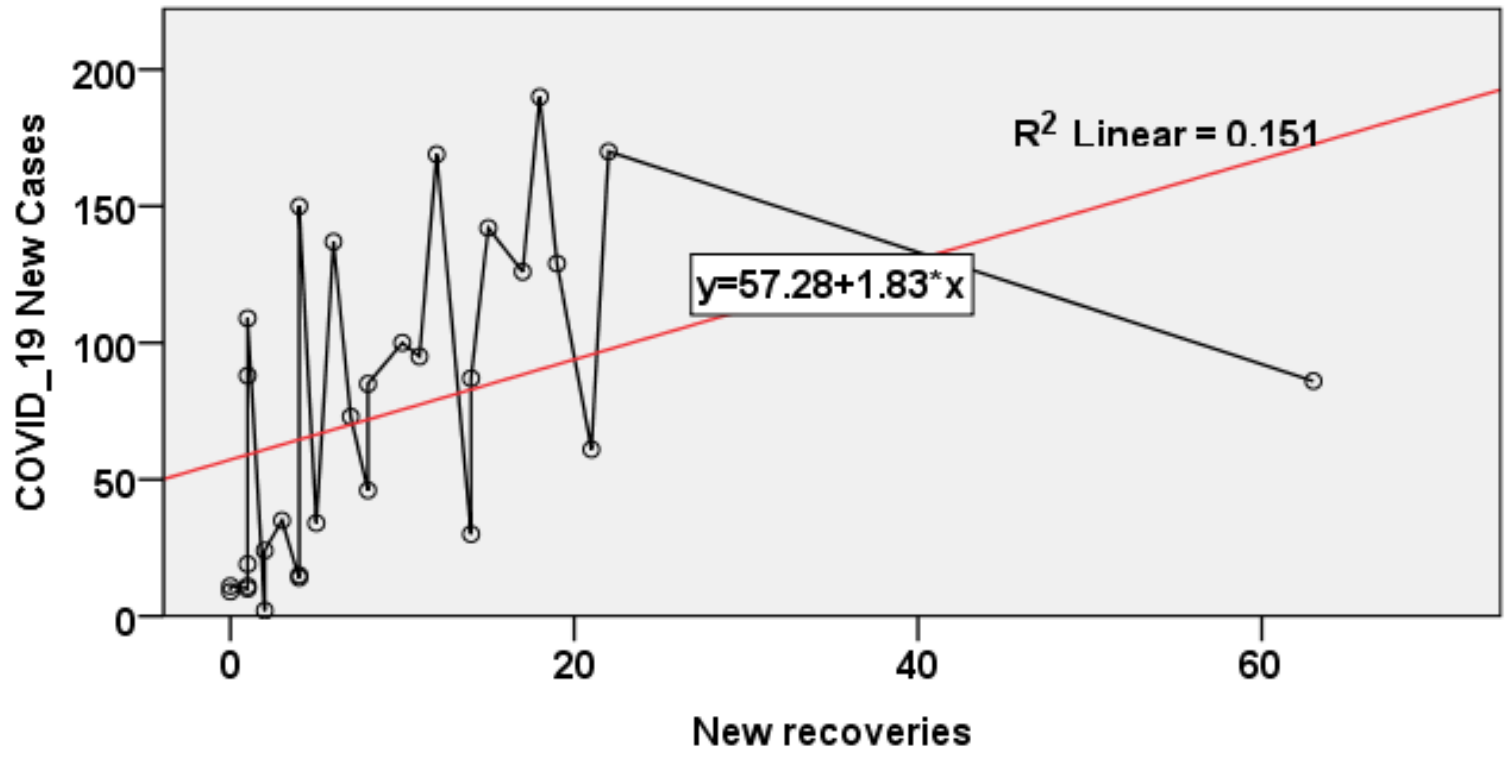

Figure 6

Simple line graph of COVID-19 new cases by new recoveries 


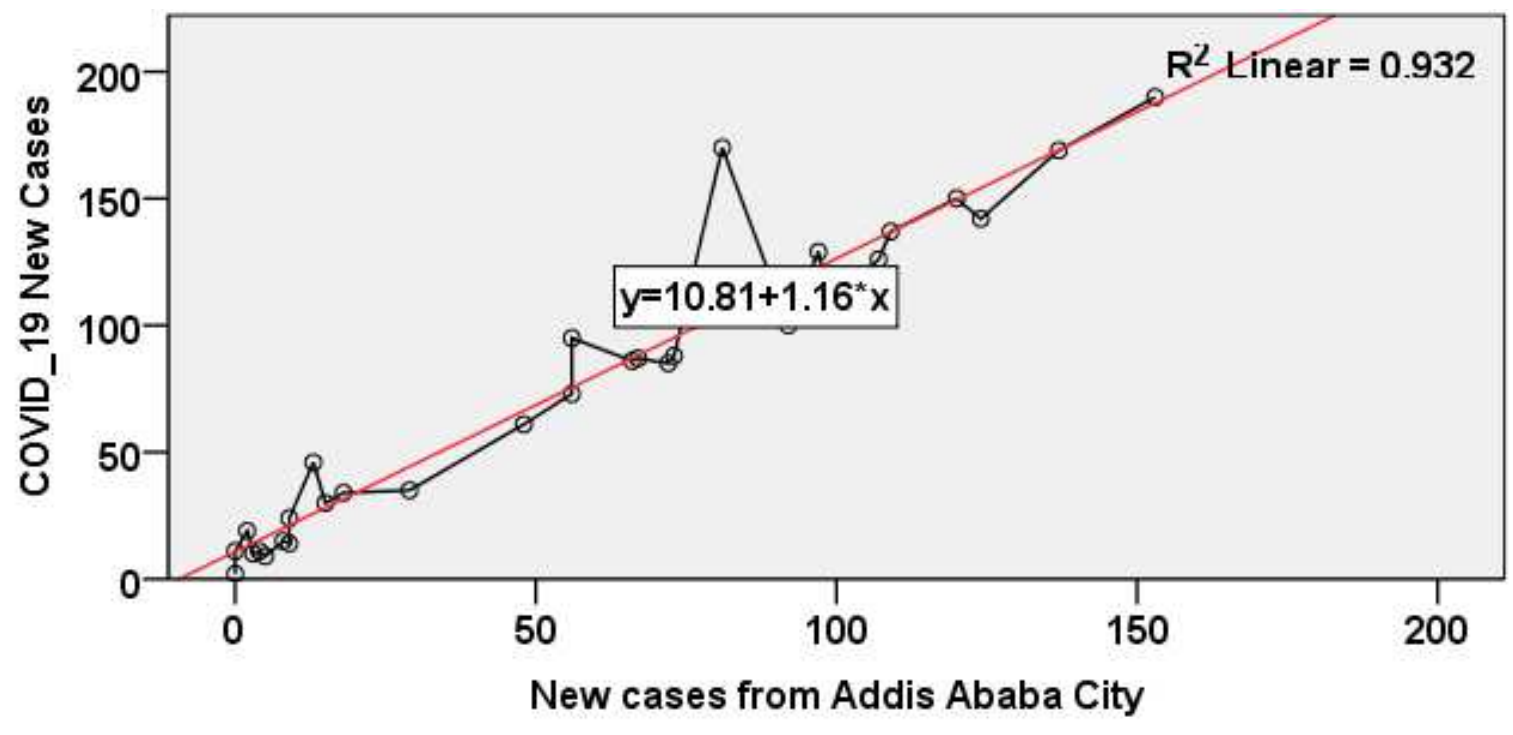

Figure 7

Simple line graph of COVID-19 new cases by new cases from Addis Ababa city

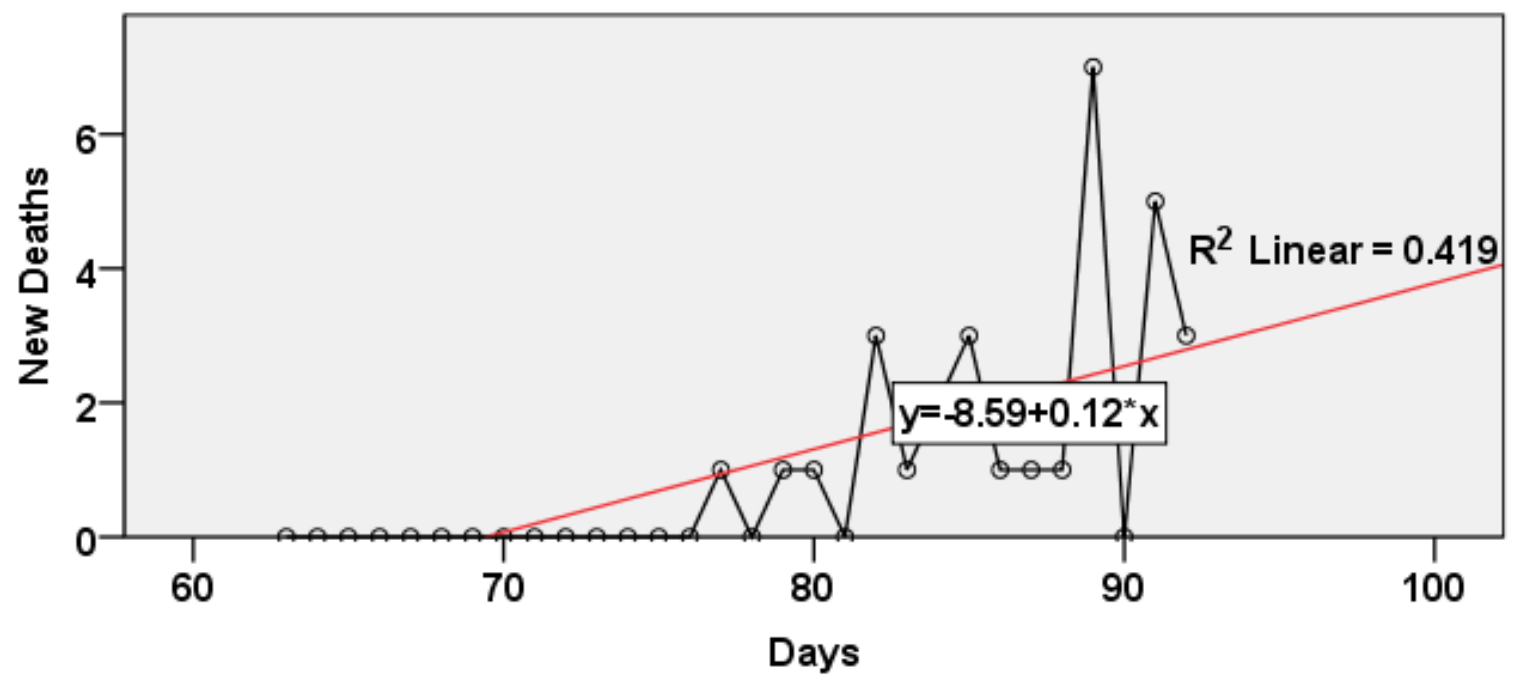

Figure 8

Simple line graph of new deaths due to COVID-19 by the number of days 


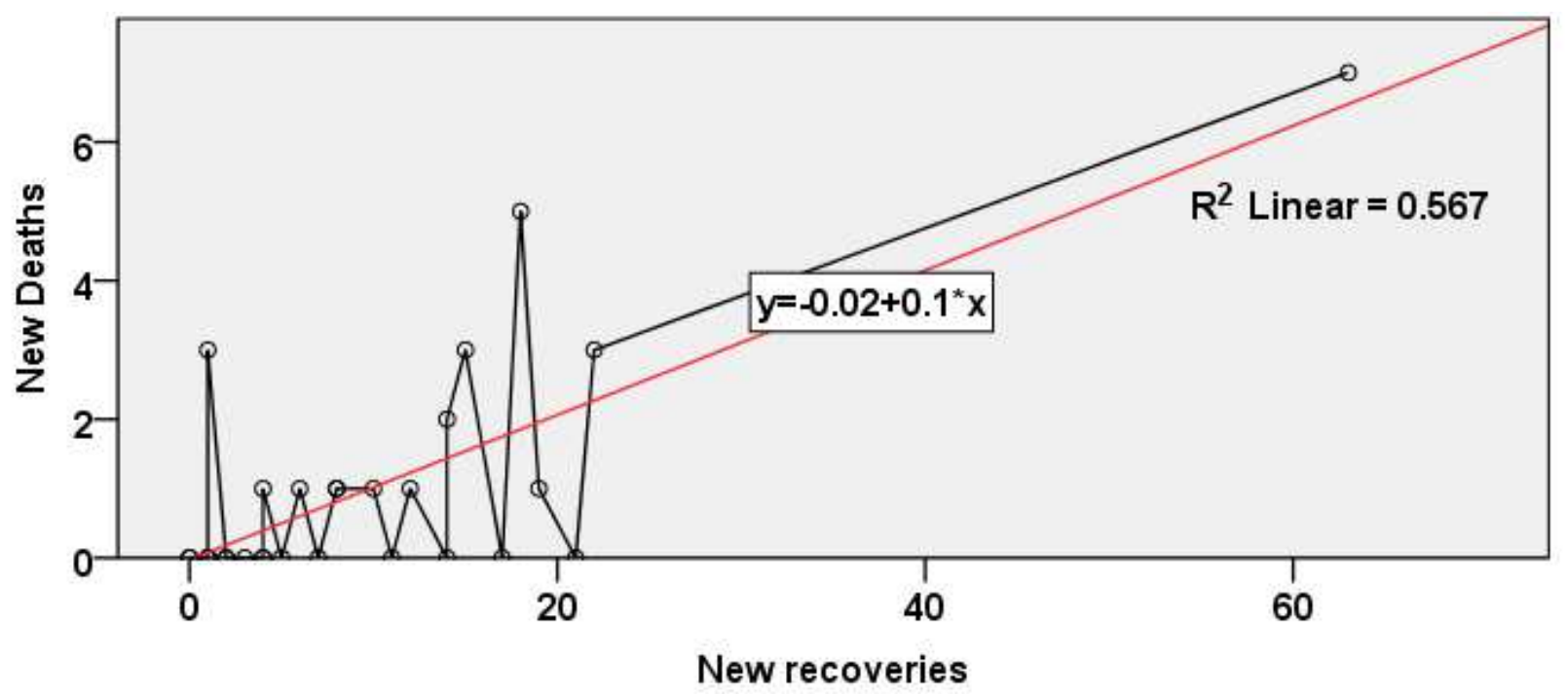

Figure 9

Simple line graph of new deaths by new recoveries

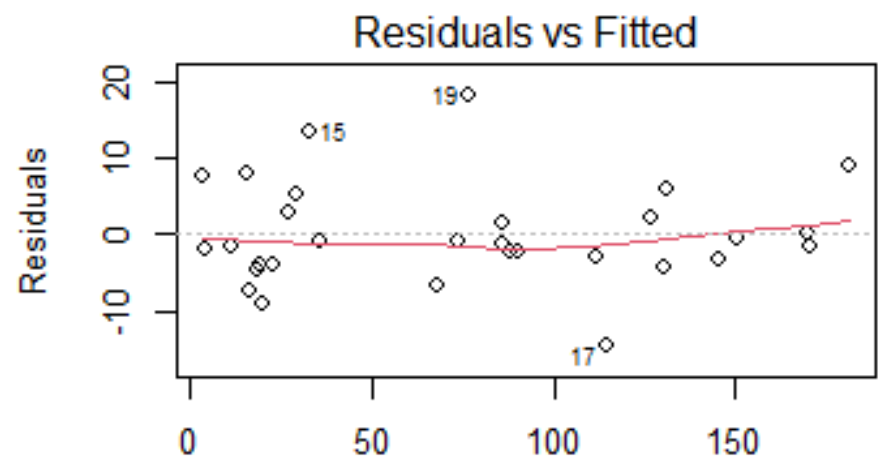

Fitted values

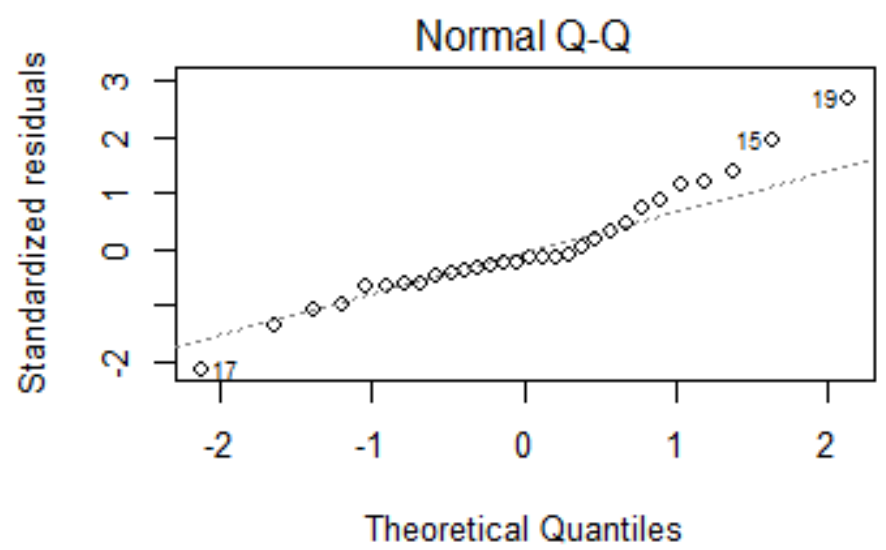

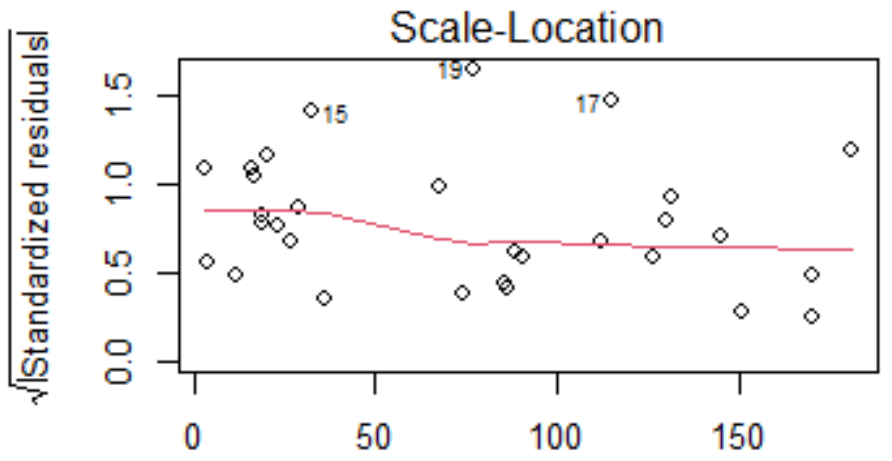

Fitted values

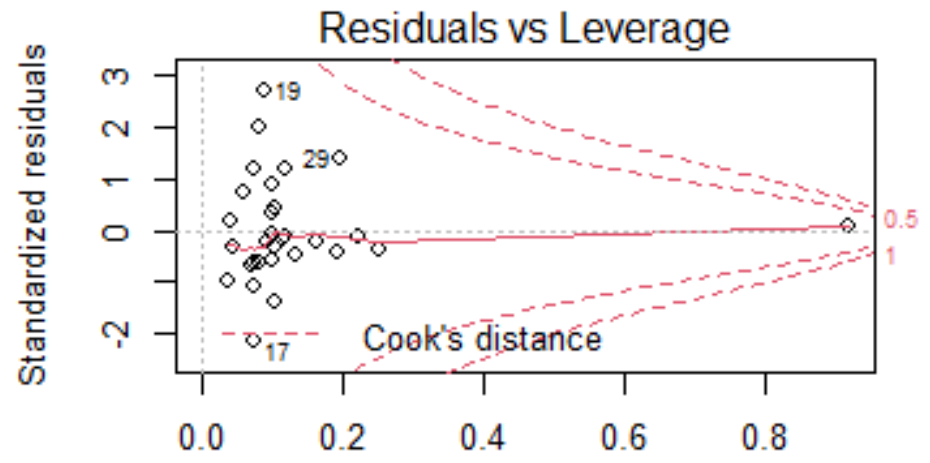

Leverage

Figure 10

R-Output of Multiple Linear Regression Assumptions 